\title{
A Foodborne botulism Occurrence in Mashhad: Clostridium botulinum in local cheese
}

\author{
Mohammad Hossein Kamaloddini ${ }^{1 *}$, Hamid Reza Kheradmand ${ }^{2}$ \\ 'Department of Toxicology, Imam Reza Hospital, Mashhad University of Medical Sciences, Mashhad, Iran \\ ${ }^{2}$ Medical School, Mashhad University of Medical Sciences, Mashhad, Iran
}

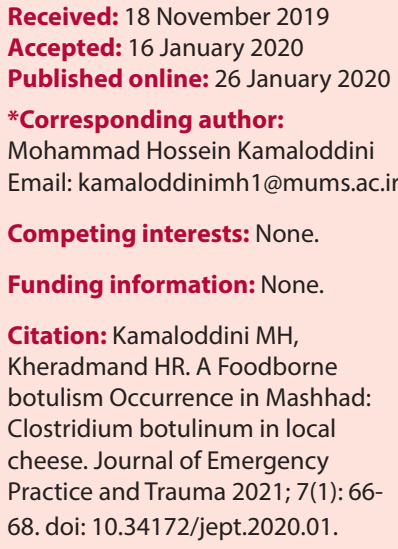

\begin{abstract}
Objective: Clostridium botulinum is one of the most common life-threatening agents all around the world which produces botulinum neurotoxin (BoNT). It may lead to morbidities such as paralysis and mortality after consuming canned tuna fish, local dairy products and home-preserved or commercial food. People use a good deal of local dairy products such as cheese and it exposes a variety of population to botulinum intoxication.

Case Presentation: A 48-year-old woman referred to the ED complaining about acute dysphonia accompanied with symmetric hypotonia and bilateral ptosis. She had a history of consuming local dairy cheese.

Conclusion: It is indispensable for the physician to identify major features of foodborne botulism in order to differentiate it from other illnesses and early initiation of intensive care for intoxicated patients. To prevent the incidence of dairy product derived botulinum, it is firmly suggested to have quality control on local dairy products.

Keywords: Foodborne botulism, Clostridium botulinum, Local cheese, Dairy products
\end{abstract}

\section{Introduction}

Foodborne botulism is caused by the anaerobic bacterial agent - Clostridium botulinum - that is a gram-positive bacteria (1) and one of the most common life-threatening agents in the United States, Europe and Iran (2-4). In 2011, 140 cases of botulism were reported to the US Centers for Disease Control and Prevention which 14\% of cases were due to food-borne botulism (5). Seven types of clostridium named A-G are studied (6) in which A, B, $\mathrm{E}$, and $\mathrm{F}$ are the main potent poisoning types in human that produce botulinum neurotoxin (BoNT). These types of clostridium get absorbed in GI after ingestion and may lead to morbidities such as paralysis and mortality, although their toxins are sensitive to heat $(4,7)$. Mostly, foodborne botulism is associated with consuming canned tuna fish, home-preserved or commercial food which contain vegetables (4,8-10). C. botulism releases neurotoxins into the blood and they bind to cells and lead to the impairment of the voluntary motor presynaptic cholinergic receptors and autonomic neuromuscular junctions (11-13). This leads to dizziness, blurred vision, slurred speech, ptosis (14) descending flaccid paralysis and respiratory failure because of the failure of transmission (11-13). All in all, the clinical symptoms can be observed after an incubation period and they are dependent on the serotype and degree of exposure to the toxin $(15,16)$.
Therefore, clinical findings are the principal key to the early diagnosis of botulism (2).

\section{Case Presentation}

A 48-year-old Caucasian woman referred to the emergency department complaining about acute dysphonia accompanied with dysarthria which cooccurred with dizziness, progressive symmetric hypotonia in upper and lower limbs, dilated pupils, facial paresthesia and bilateral ptosis. She had no dysphagia, fever, respiratory distress or vertigo. She had a history of consuming local dairy cheese. Based on clinical findings, the patient was admitted with the impression of botulinum intoxication. Botulism anti-toxin was administered. One vial of tetravalent botulism antitoxin was given intravenously as a $1: 10 \mathrm{vol} / \mathrm{vol}$ dilution in $0.9 \%$ sodium chloride TDS. Since the most common cause of mortality is respiratory failure (17), supportive care was prepared and $\mathrm{O}_{2}$ therapy, cardiac monitoring, pulse oximetry, and rapid sequence intubation equipment were considered and prepared in case of necessity. To rule out other probable causes, a neurology consult was requested. Blood and feces sample were taken and the probable occurrence of botulism was informed to the Health Center. The patient gradually became better. On the fifth day, the patient still had dysphonia and perioral paresthesia. She was hospitalized 
for 11 days and discharged after recovering and stable conditions. Tables 1 and 2 show laboratory data.

\section{Discussion}

In our case, early diagnosis and treatment were based on clinical findings obtained by history taking and physical exam. Data on history revealed the consumption of a suspicious dairy product and findings in the physical exam identified neuromuscular presentations such as the decreased force of limbs, dilated pupils and ptosis. Botulinum intoxicated patients most often do not present paresthesia (18) but in our case, the patient suffered from facial paresthesia. This finding is in line with other cases reported in the united states, San Francisco (19) and Atlanta, Georgia (20) especially in patients who were poisoned with BoNT type A or B.

It is important to differentiate botulism and other central nervous system deficits which may mimic botulism such as Guillain-Barre syndrome, Myasthenia Gravis and Lambert-Eaton myasthenic syndrome $(3,9)$. These patients usually have fever, ataxia and elevated cerebrospinal fluid (CSF) protein, but they often have normal pupils $(18,21)$. Central neural damages with asymmetric weakness should be considered in these patients. Ruling out central neurological damages can be performed by an appropriate module of radiologic imaging or electromyography/nerve conduction study. It is recommended to take samples from serum, stool and contaminated substances (22), so it would be possible to confirm the diagnosis.

\section{Conclusion}

It is essential to consider other possible etiologies with similar symptoms such as thallium, CO intoxication, and electrolytes abnormalities, foremost hypokalemia, and hyperkalemia which may present with dyspnea, palpitation, vomiting, and myalgia. Laboratory tests and imaging may help to exclude other diagnoses, but it is indispensable for the physician to identify major features of foodborne botulism in order to differentiate it from other illnesses, therefore, it would be possible to initiate treatment and supportive cares. Also, it is firmly suggested to have quality control on dairy products to prevent the incidence of botulinum intoxication.

\section{Authors' contributions}

MHK conceived and planned the experiment and carried it out. Data acquisition and obtaining findings were done by HRK. HRK wrote the manuscript with support from MHK. All authors read and approved the final manuscript.

\section{Ethical Issues}

Ethical issues have been completely observed by authors.

\section{References}

1. Pourshafie MR, Saifie M, Shafiee A, Vahdani P, Aslani M, Salemian J. An outbreak of food-borne botulism associated
Table 1. Laboratory data: ABG test at admission and on the second day of hospitalization

\begin{tabular}{lcc}
\hline Test Name & Day $\mathbf{1}$ Result & Day 2 Result \\
\hline $\mathrm{pH}$ & 7.39 & 7.41 \\
$\mathrm{PO}_{2}(\mathrm{~mm} \mathrm{Hg})$ & 56 & 53 \\
$\mathrm{PCO}_{2}(\mathrm{~mm} \mathrm{Hg})$ & 36 & 31 \\
$\mathrm{HCO}_{3}(\mathrm{mEq} / \mathrm{L})$ & 21.8 & 19.6 \\
$\mathrm{O} 2$ saturation $(\%)$ & 88 & $87 \%$ \\
\hline
\end{tabular}

Table 2. Laboratory data: blood test results at admission

\begin{tabular}{lc}
\hline Test Name & Result \\
\hline Blood sugar (mg/dL) & 99 \\
\hline Urea (mg/dL) & 32 \\
Cr (mg/dL) & 0.7 \\
$\mathrm{Na}(\mathrm{mEq} / \mathrm{L})$ & 136 \\
$\mathrm{~K}(\mathrm{mEq} / \mathrm{L})$ & 4.0 \\
\hline $\mathrm{Ca}(\mathrm{mg} / \mathrm{dL})$ & 9.7 \\
\hline Total bilirubin $(\mathrm{mg} / \mathrm{dL})$ & 1.3 \\
\hline Direct bilirubin $(\mathrm{mg} / \mathrm{dL})$ & 0.3 \\
\hline AST (U/L) & 17 \\
\hline ALT (U/L) & $24 \mathrm{U} / \mathrm{L}$ \\
\hline Alp (U/L) & $176 \mathrm{U} / \mathrm{L}$ \\
\hline TPi (high-sensitive) & 5.6 \\
\hline COHb & $<10 \%$ \\
\hline a & \\
\hline
\end{tabular}

a Negative $<19$.

with contaminated locally made cheese in Iran. Scand J Infect Dis 1998; 30(1): 92-4. doi: 10.1080/003655498750002385.

2. Hellmich D, Wartenberg KE, Zierz S, Mueller TJ. Foodborne botulism due to ingestion of home-canned green beans: two case reports. J Med Case Rep 2018; 12(1): 1. doi: 10.1186/ s13256-017-1523-9.

3. Nejadrahim R, Delirrad M. Foodborne Botulism: A Study of 57 Cases in Northwest Iran. Iranian Journal of Toxicology 2016; 10(6): 45-50. doi: 10.29252/arakmu.10.6.45.

4. Seyboldt C, Discher S, Jordan E, Neubauer H, Jensen KC, Campe A, et al. Occurrence of Clostridium botulinum neurotoxin in chronic disease of dairy cows. Vet Microbiol 2015; 177(3-4): 398-402. doi: 10.1016/j.vetmic.2015.03.012.

5. Centers for Disease Control and Prevention (CDC). National Enteric Disease Surveillance: Botulism Annual Summary, 2011. Atlanta, Georgia: US Department of Health and Human Services, CDC; 2011.

6. Suen JC, Hatheway CL, Steigerwalt AG, Brenner DJ. Clostridium argentinense sp. nov.: a genetically homogeneous group composed of all strains of Clostridium botulinum toxin type $G$ and some nontoxigenic strains previously identified as Clostridium subterminale or Clostridium hastiforme. Int J Syst Evol Microbiol 1988; 38(4): 375-81. doi: 10.1099/00207713-38-4-375.

7. Mehdi Zadeh M, Rahimi Fard N, Pirouz B, Khezri M, Zavar M. A Review on Botulism. Journal of Shahid Sadoughi University of Medical Sciences 2008; 16(3): 88-96. [In Persian].

8. Anniballi F, Chironna E, Astegiano S, Fiore A, Auricchio B, 
Buonincontro G, et al. Foodborne botulism associated with home-preserved turnip tops in Italy. Ann Ist Super Sanita 2015; 51(1): 60-1. doi: 10.4415/ann_15_01_10.

9. Shahcheraghi F, Nobari S, Vahdani P, Majdian J, Aslani MM. Type A Botulism in Members of a Family Following the Consumption of Locally Made Cheese. Journal of Mazandaran University of Medical Sciences 2013; 22(96): 124-9. [In Persian].

10. McCarty CL, Angelo K, Beer KD, Cibulskas-White K, Quinn K, de Fijter S, et al. Large outbreak of botulism associated with a church potluck meal--Ohio, 2015. MMWR Morb Mortal Wkly Rep 2015; 64(29): 802-3. doi: 10.15585/mmwr.mm6429a6.

11. Bergeron G, Latash J, Da Costa-Carter CA, Egan C, Stavinsky F, Kileci JA, et al. Notes from the Field: Botulism Outbreak Associated with Home-Canned Peas - New York City, 2018. MMWR Morb Mortal Wkly Rep 2019; 68(10): 251-2. doi: 10.15585/mmwr.mm6810a5.

12. Dave GA. A rapid qualitative assay for detection of Clostridium perfringens in canned food products. Acta Biochim Pol 2017; 64(2): 207-13. doi: 10.18388/ abp.2015_1169.

13. Rosow LK, Strober JB. Infant botulism: review and clinical update. Pediatr Neurol 2015; 52(5): 487-92. doi: 10.1016/j. pediatrneurol.2015.01.006.

14. Chung GT, Kang DH, Yoo CK, Choi JH, Seong WK. The first outbreak of botulism in Korea. Korean J Clin Microbiol 2003; 6(2): 160-3.

15. Feng L, Chen X, Liu S, Zhou Z, Yang R. Two-family outbreak of botulism associated with the consumption of smoked ribs in Sichuan Province, China. Int J Infect Dis 2015; 30: 74-7. doi: 10.1016/j.ijid.2014.10.008.

16. Wells CL, Wilkins TD. Clostridia: Sporeforming Anaerobic Bacilli. In: Baron S, ed. Medical Microbiology. Galveston (TX): University of Texas Medical Branch at Galveston; 1996.

17. Wongtanate $\mathrm{M}$, Sucharitchan $\mathrm{N}$, Tantisiriwit $\mathrm{K}$, Oranrigsupak P, Chuesuwan A, Toykeaw S, et al. Signs and symptoms predictive of respiratory failure in patients with foodborne botulism in Thailand. Am J Trop Med Hyg 2007; 77(2): 386-9.

18. Proverbio MR, Lamba M, Rossi A, Siani P. Early diagnosis and treatment in a child with foodborne botulism. Anaerobe 2016; 39: 189-92. doi: 10.1016/j.anaerobe.2015.12.002.

19. Goode GB, Shearn DL. Botulism: a case with associated sensory abnormalities. Arch Neurol 1982; 39(1): 55. doi: 10.1001/archneur.1982.00510130057015.

20. Dembek ZF, Smith LA, Rusnak JM. Botulism: cause, effects, diagnosis, clinical and laboratory identification, and treatment modalities. Disaster Med Public Health Prep 2007; 1(2): 122-34. doi: 10.1097/DMP.0b013e318158c5fd.

21. Nelson LS, Hoffman RS, Howland MA, Lewin NA, Goldfrank LR. Goldfrank's Toxicologic Emergencies. 11th ed. McGraw-Hill Education/Medical; 2018.

22. Thirunavukkarasu N, Johnson E, Pillai S, Hodge D, Stanker L, Wentz T, et al. Botulinum neurotoxin detection methods for public health response and surveillance. Front Bioeng Biotechnol 2018; 6: 80. doi: 10.3389/fbioe.2018.00080. 